UDC 004.5:004.78

DOI: 10.15587/2706-5448.2021.238846

Article type «Reports on Research Projects»

\section{Yevhen Artamonov, Viktoria Borisevich, Iurii Golovach}

\title{
ANALYSIS OF THE IMPLEMENTATION OF A MULTI-SCENARIO DECISION SUPPORT SYSTEM IN THE TREATMENT OF LUNG CANCER
}

The object of the research is the decision support system in the treatment of lung cancer, the subject of the research - the use of a multi-scenario interface in the construction of decision support systems. One of the problem areas in software development is the need for multi-criteria adaptation of interfaces to users. This problem became especially acute after the introduction of quarantine when various automation systems began to develop rapidly, aimed at reducing direct contact between the customer and the service provider. If earlier software users were the more or less related group, now the difference began not only at the level of technical qualifications. Now, when developing software, more attention should be paid to physiological and psychological differences between users, features of hardware and software, environment, and other criteria. In the current situation, it turned out that in most cases automated systems are used by persons who are not interested in these systems but simply have to use them. One of the options for solving this problem is to create an adaptive universal interface. This research is aimed at analyzing methods for implementing multi-scenario decision support systems in the treatment of lung cancer. In the research, attention is paid to the following aspects: adaptive intelligent interface, architecture and structure of the adaptive intelligent interface, algorithms for the functioning of agents of adaptive system interfaces. In the research, the system was used by 500 participants for 30 days. The benchmark was the type of data display scenario selected at the start and end of the day. The research showed a gradual transition of users to scenarios of higher complexity, which involve the analysis of all available information. The tendency of reverse transitions decreases with time, and from the $18^{\text {th }}$ day of using the system, the type of the selected interface changes in rare moments. These results proved the possibility of using automatically configurable interfaces, and bringing them to the final form will be achieved in 18-20 days of using the system.

Keywords: adaptive interface, decision support systems, medical diagnostic systems, multi-scenario systems.

\section{How to cite}

Artamonov, Y., Borisevich, V., Golovach, I. (2021). Analysis of the implementation of a multi-scenario decision support system in the treatment of lung cancer. Technology Audit and Production Reserves, 5 (2 (61)), 33-38. doi: http://doi.org/10.15587/2706-5448.2021.238846

\section{Introduction}

With the implementation of quarantine, in connection with the pandemic, almost all areas of human activity have changed, namely the transfer of most activities to an online format (even consultations with doctors if possible are held in online conferences). This transition has led to the rapid development of various automation systems that aim to reduce direct contact between the customer and the service provider.

It was at this point that the developers of automated systems faced the problem of adapting interfaces for people who have no experience in working with software systems. Until now, in most cases, automated systems have been used by users and/or specialists in the field whose activities have been automated who are directly interested in these systems. To the requirements of users in the preferences, views, purposes of use of automated systems were added the task of taking into account different levels of technical training and a variety of technical equipment.

In the case of the mass use of an automated system, the usability of the interface is one of the key factors determining the choice of this system in the software market.

Research in the direction of multi-agent and multi-scenario systems has recently become very popular. The applicability of these approaches is used in almost any field. More than 50 articles from various scientific fields were studied, which describe approaches to the implementation of multi-agent and multi-scenario systems. The closest to our approach is the work [1], which is devoted to decision support systems in health care, and the work [2], which reveals the issue of informing the public about issues in the medical field.

All scientific research confirms the expanded possibilities of the proposed approaches. At this time, theoretical research has been completed and the stage of practical implementation of the decision support system in the treatment 
of lung cancer has begun. This system is intended for use by both healthcare professionals and users undergoing examination or treatment. The system also provides for the use of medical and pharmaceutical facilities by administrative staff.

Such use of the system involves different levels of data disclosure not only for the roles that are defined for each user of the system but also to use the system. Thus, a specialist in the analysis of biopsy results does not need information on the main screen about the results of other examinations, although it has access to them (according to the role of a health worker) and can view them in a separate window). Implemented hiding and organizing information in the developed system is carried out both through the settings and in automatic mode, in case of non-use of certain sections.

There are 2 scenarios of displaying information for each role: full and abbreviated, which is formed by the activity of the use of units of the system.

The research, which is covered in this paper, is devoted to the analysis of the use of these scenarios and aims to determine the correctness of the chosen decision to implement the system.

The issue of automatic configuration of interfaces has always been of great importance in software development (software), but the mass transition of users to work with online systems has made this task one of the most pressing.

Thus, the object of research was chosen decision support system in the treatment of lung cancer, and the subject of the research - the use of a multiscenario interface in the construction of decision support systems. The purpose of the work is to analyze the implemented automatic adjustment of the system interface to the needs of users.

\section{Methods of research}

The analysis of the developed software system provides a number of aspects that determine the parameters to be analyzed and methods of analysis. Thus, the analysis of the structure of the software involves the analysis of functional requirements and modes of operation of the system. And the analysis of the made decisions concerning mechanisms of adjustment of interfaces demands supervision of actions of users during work with the system.

During development medical decision support systems (MSMEs) are important in the presentation and visualization of pathognomonic symptoms, because they are sufficient to establish a reliable diagnosis. But the number of pathognomonic symptoms is strictly limited, they do not always manifest themselves in the relevant diseases and not at all stages of the disease, forms and variants of its course. That is why the diagnosis is mainly focused on non-specific and specific symptoms, especially in their combination [3].

When constructing a decision support system for the treatment of lung cancer, descriptions of syndromes and treatments were not developed independently but were formed on the basis of protocols of leading associations for cancer treatment NCCN (National Comprehensive Cancer Network) [4] and Cancer Research UK [5, 6].

When examining the patient, the doctor essentially recognizes the visual, sound, temperature and other images on the basis of which it makes a diagnosis. It is necessary to limit direct contact between patients and doctors in a difficult epidemiological situation. It is the use of widely used computer diagnostic systems that makes this possible. The main purpose of such systems is to reduce the waiting time for intermediate results in collecting the data needed by the doctor to make a final decision [7].

When developing the system, which is currently undergoing an experimental operation, it was first necessary to conduct research to determine a sufficient information space of the parameters necessary for the formation of the diagnosis.

The development of the system was based on a formalized view of the assessment of the state of the organism through its interaction with the external environment, which is presented in Fig. 1.

The optimum functioning of each subsystem of the body is determined by its ultimate beneficial effect (UBE), the parameters of which are perceived by the receptor subsystems and transmitted to the central nervous system (CNS).

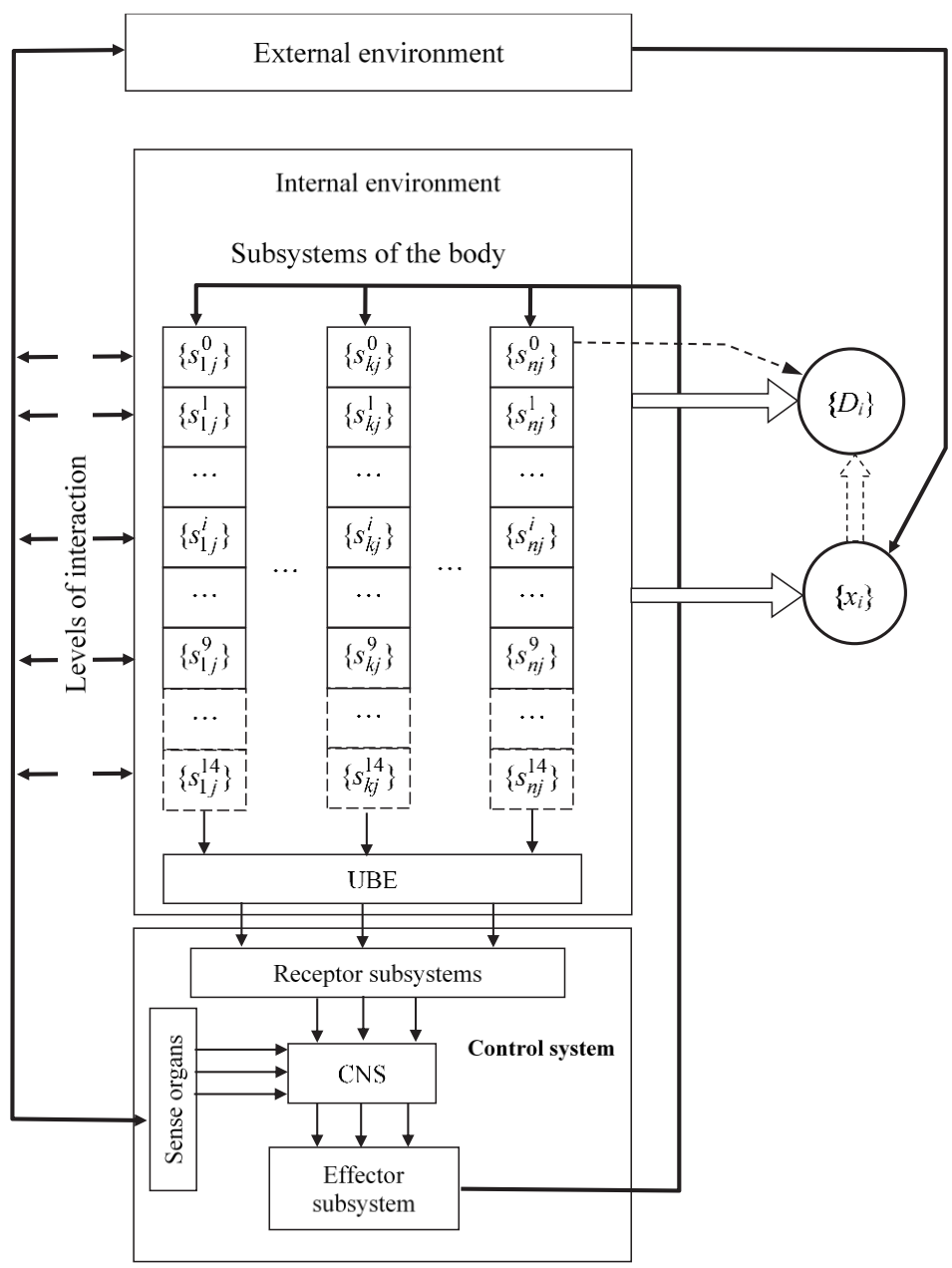

Fig. 1. The scheme of interrelations of a condition - signs - diagnosis

In this case, at each $k$-th level of interaction of the internal and external environment, each $i$-th subsystem of the organism $R_{i}$ (cardiovascular, respiratory, nervous, immune, etc.) is in a certain $j$-th state $s_{i j}^{k}$ from the set:

$$
S_{i}=\left\{s_{i j}^{k}\right\} ; \quad k=\overline{0.14} ; \quad i=\overline{1, n_{k}} ; \quad j=\overline{1, n_{i}},
$$

where $n_{k}$ - the number of subsystems of the organism at the $k$-th level of interaction with the environment; $n_{i}-$ the number 
of possible states of the $i$-th subsystem at the $k$-th level.

The set of states $S_{i}$ is conditionally divided into subsets: $S_{i n}-$ norm, $S_{i g}-$ border state, $S_{i p}$ pathology:

$$
S_{i}=S_{i n} \cup S_{i g} \cup S_{i p} .
$$

The set $D$ determines the diagnoses in accordance with the $X-$ set of parameters. These issues are considered in more detail in [8].

In the decision support system for the treatment of lung cancer, developers have the following problems [9]:

1) analysis of biosignals and medical images;

2) assessment of the informativeness of diagnostic signs;

3) synthesis of decisive rules on the basis of which the decision on the diagnosis is made.

However, the implementation of such systems is possible only with a complete description of the procedure of medical examinations and storage in one place of the results of these examinations [10], because it is impossible to collect enough signs and inadmissible to force patients to conduct optional examinations (very expensive).

To obtain these indicators, the following examinations are used (Fig. 2): computed tomography (CT), bronchoscopy, biopsy, histology, immunohistochemistry (IHC), positron emission tomography (PET).

To enter the results of the surveys, a sequence of actions was developed, which provided for the order of transitions between the windows of the system (Fig. 3), this sequence is similar for all types of surveys.

On the basis of the presented tree windows of the system which provided data input (Fig. 4) and their transfer to the medical worker for the formation of the conclusion (Fig. 5).

The system analyzes the obtained data for sufficiency and transmits the survey results. The results are transmitted either to the healthcare professional assigned to the user or to the freelance healthcare professional with the highest level of trust if the user has not yet chosen the healthcare professional to lead him/her.

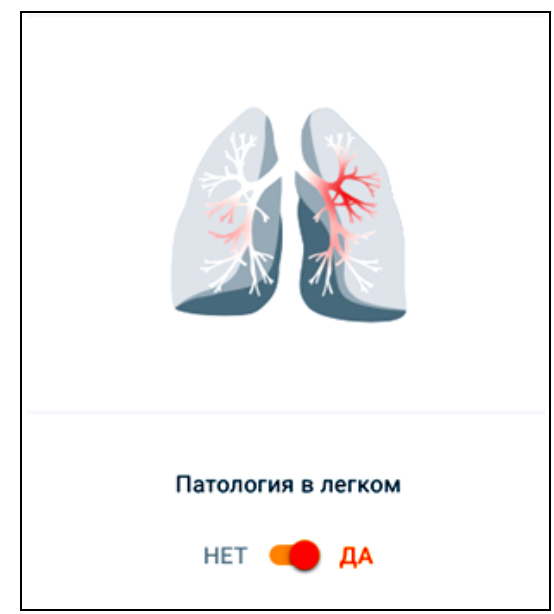

a

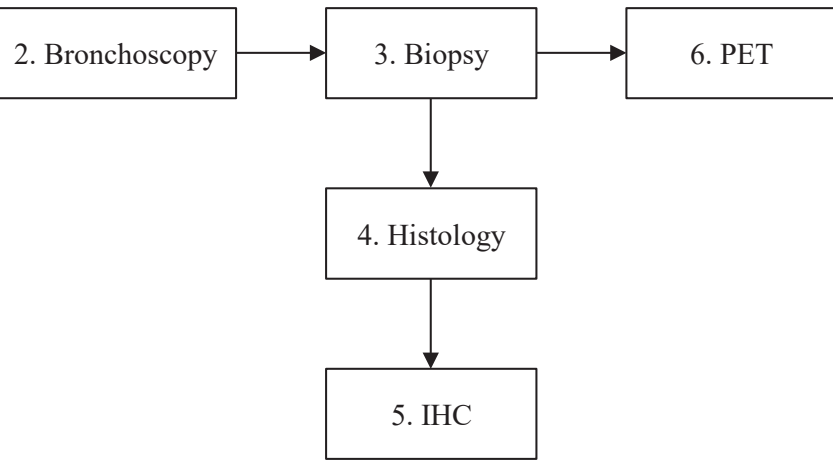

Fig. 2. The procedure for conducting surveys

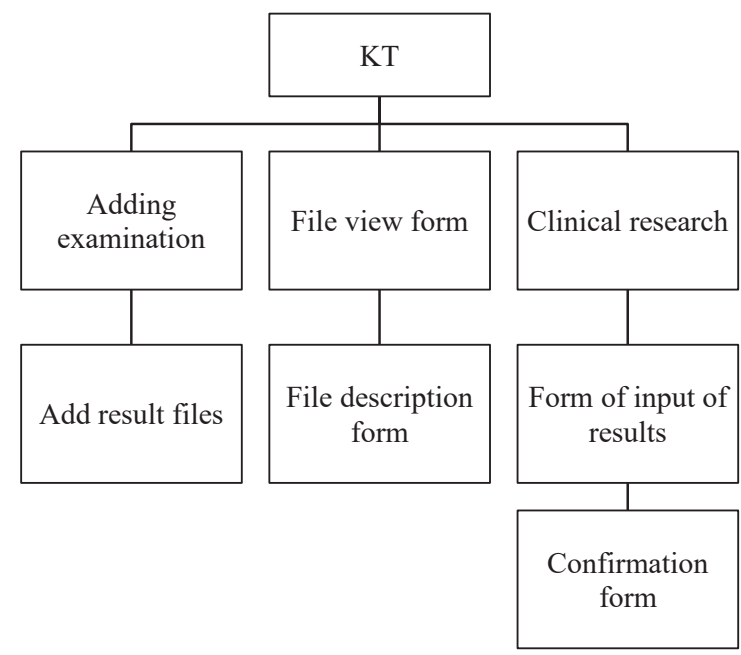

Fig. 3. Diagnostic procedures and data entry control

After processing the received data by a medical professional and checking the diagnosis made by the system, the diagnosis is confirmed by a medical professional with the possibility of making adjustments that are noted in the system. The result is sent to the patient (Fig. 6).

IN system built more than 40 rules by the method «IFTHEN» in accordance with the protocols of NCCN [11], which allowed the developed system to cover the entire tree of the conclusion, which provides an unambiguous diagnosis based on the introduced features.

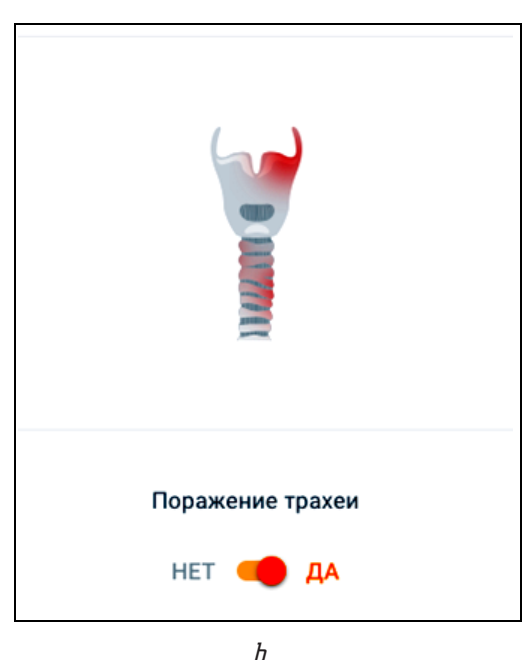

Fig. 4. Windows of the decision support system in the treatment of lung cancer: a - determining the location of the pathology; $b$ - the presence of tracheal lesions 


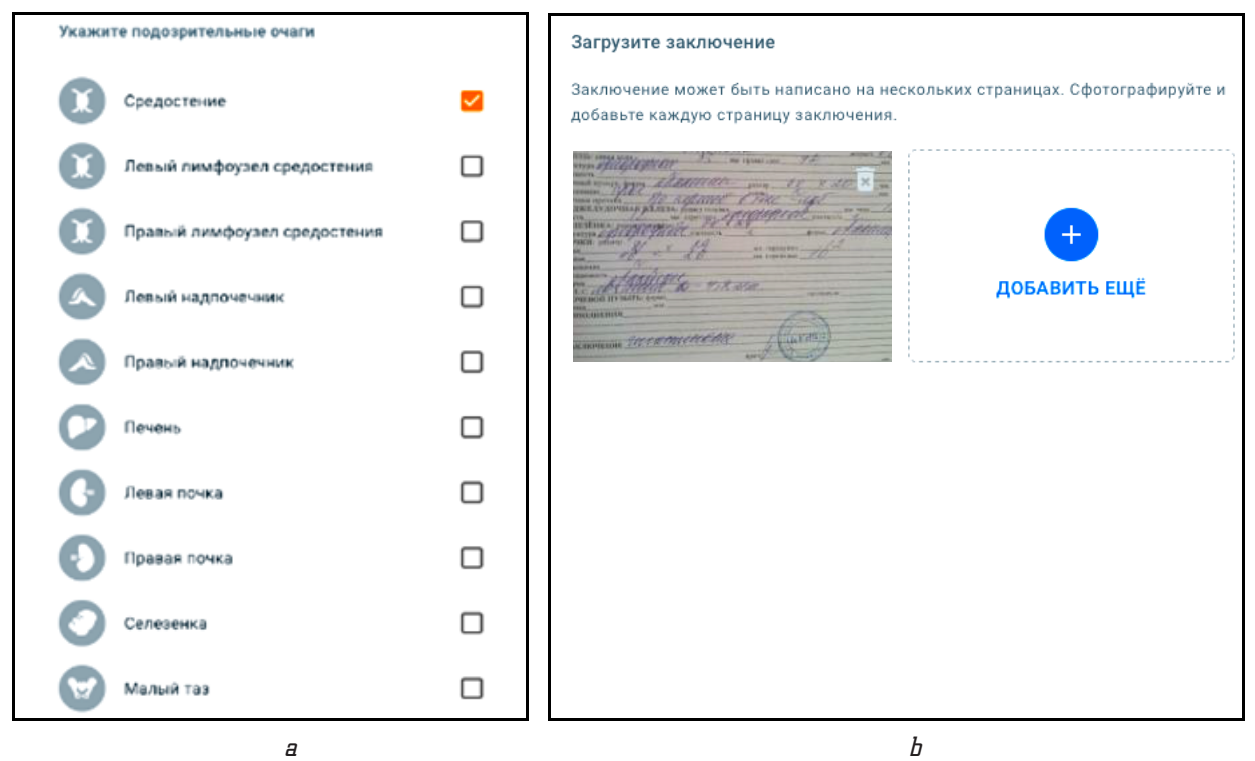

Fig. 5. Windows of survey results: $a$ - suspicious lesions; $b$ - conclusion form

\section{$\equiv$ DR DOCTORIGHT}

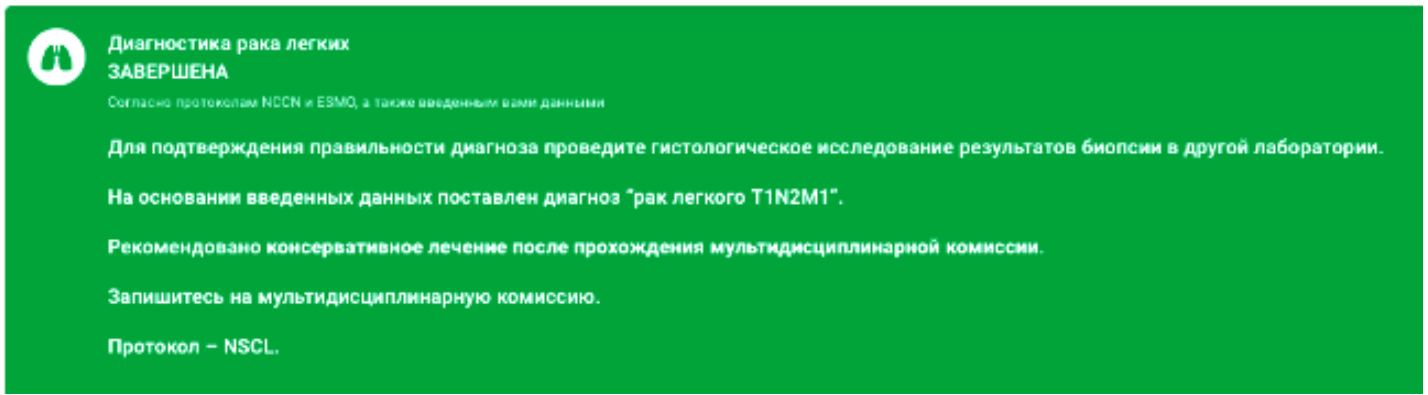

Fig. 6. Screenshot of the window with the established system of the diagnosis

To analyze the mechanism of automatic configuration of interfaces in the system, a module for collecting information was installed for each operation of changing the mode of presentation of information. To reduce the amount of input information for the research, only the data of the end-user mode per session were taken.

\section{Research results and discussion}

The proposed multi-scenario interface approach for each user role was used to build a decision support system in the treatment of lung cancer. The research involved 500 participants for 30 days, controlled the type of selected scenario of data display at the beginning and end of the day (Table 1). On average, users worked with the system for 25-30 minutes a day.

It is possible to note gradual transition to scenarios of higher complexity in the system which provides the analysis of all available information. This trend decreases over time and in a month comes to a steady-state (Fig. 7).

As a result, after rapid and abrupt changes in the first 10 days, after the introduction of a new interface configuration mechanism, there was a slow change in the number of users in each of the scenarios (Fig. 8). The number of users in the simplified scenario was slowly decreasing, and in the full scenario, it was slowly increasing.
These data prove the correctness of the chosen solution, which allows to start full-fledged work without manual settings in unfamiliar software. The system has a manual adjustment mechanism, but after the introduction of the automatic interface adjustment mechanism, only 7 users out of $500(1.4 \%)$ used this option.

This research is the first of a planned series of researches on the use of SME interfaces with automatic adaptation to user behavior. This research was aimed only at confirming the hypothesis about the direction of change of interface scenarios with increasing user time with the system.

The disadvantage of the research is the lack of a control group and the restriction to only two presentation scenarios, which may not fully coincide with the wishes of users regarding the interface. But this was due to the update of the entire system and the inability to support multiple versions for public use. The new version of the system is expected to use 5 standard scenarios.

In addition, the research did not take into account indicators that could influence the choice of scenario:

- experience in the system;

- type and direction of user activity;

- basic settings.

These parameters will be taken into account when conducting new research. 
Use of scenarios in the decision support system in the treatment of lung cancer

\begin{tabular}{|c|c|c|c|c|}
\hline Day & $\begin{array}{c}\text { 5cenario } 1 \\
\text { at the beginning of the day }\end{array}$ & $\begin{array}{l}\text { Change the scenario } \\
\text { at the end of the day }\end{array}$ & $\begin{array}{c}\text { Scenario } 2 \\
\text { at the beginning of the day }\end{array}$ & $\begin{array}{l}\text { Change the scenario } \\
\text { at the end of the day }\end{array}$ \\
\hline 1 & 500 & 29 & 0 & 0 \\
\hline 2 & 471 & 34 & 29 & 2 \\
\hline 3 & 439 & 33 & 61 & 2 \\
\hline 4 & 408 & 26 & 92 & 1 \\
\hline 5 & 383 & 25 & 117 & 1 \\
\hline 6 & 359 & 19 & 141 & 2 \\
\hline 7 & 342 & 12 & 158 & 2 \\
\hline 8 & 332 & 13 & 168 & 2 \\
\hline 9 & 321 & 14 & 179 & 3 \\
\hline 10 & 310 & 11 & 190 & 2 \\
\hline 11 & 301 & 7 & 199 & 4 \\
\hline 12 & 298 & 7 & 202 & 2 \\
\hline 13 & 293 & 8 & 207 & 1 \\
\hline 14 & 286 & 6 & 214 & 1 \\
\hline 15 & 281 & 9 & 219 & 2 \\
\hline 16 & 274 & 9 & 226 & 3 \\
\hline 17 & 268 & 11 & 232 & 2 \\
\hline 18 & 298 & 10 & 202 & 2 \\
\hline 19 & 290 & 10 & 210 & 0 \\
\hline 20 & 280 & 8 & 220 & 1 \\
\hline 21 & 273 & 9 & 227 & 0 \\
\hline 22 & 264 & 7 & 236 & 1 \\
\hline 23 & 273 & 4 & 227 & 0 \\
\hline 24 & 274 & 6 & 226 & 2 \\
\hline 25 & 258 & 7 & 242 & 0 \\
\hline 26 & 259 & 5 & 241 & 1 \\
\hline 27 & 255 & 5 & 245 & 1 \\
\hline 28 & 251 & 7 & 249 & 0 \\
\hline 29 & 244 & 6 & 256 & 0 \\
\hline 30 & 238 & 4 & 262 & 1 \\
\hline 31 & 235 & 7 & 265 & 0 \\
\hline Result & 228 & - & 272 & - \\
\hline
\end{tabular}

Number of changed scenarios by working days

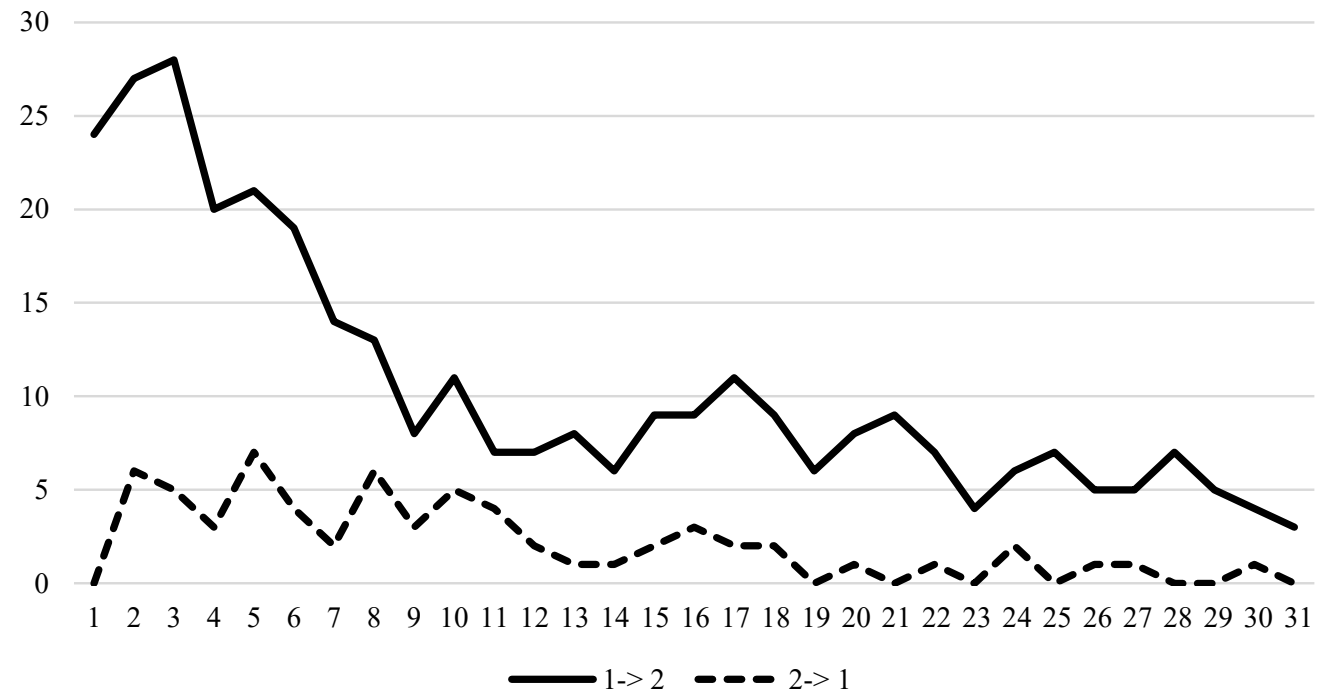

Fig. 7. Graphs of the number of changed scenarios by working days 
Selected scenarios by working days

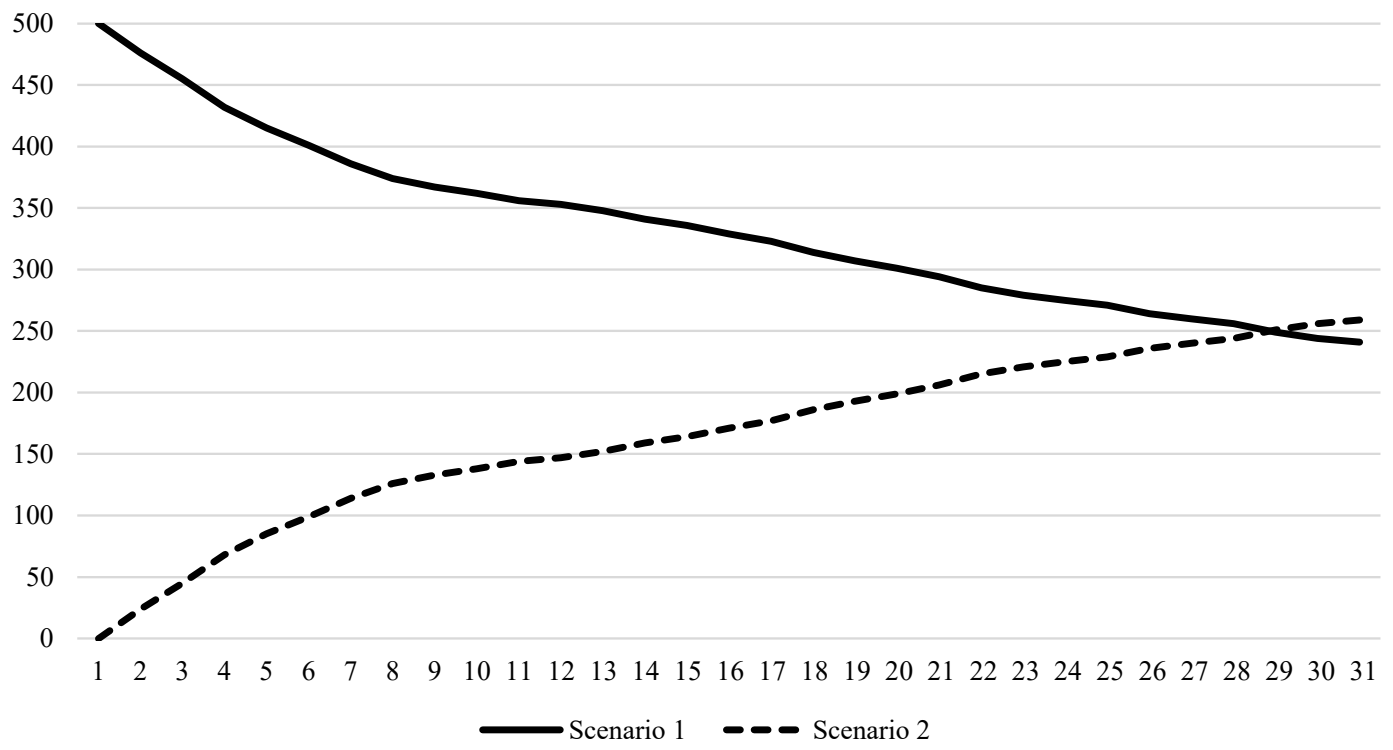

Fig. 8. Graphs of the number of users in each of the scenarios by working days

\section{Conclusions}

The multi-scenario approach allowed to present the results of diagnostics taking into account the available data and the level of qualification of the system users.

The research monitored the work of 500 users in the mode of automatic configuration of the interface. This research allowed to note the following points:

- in the first days of the launch of the new mechanism of adjustment of the interface there was an abrupt change in the number of users;

- from the $10^{\text {th }}$ day of using the system with the new mechanism, the transitions to the simplified interface were not more than 4 per day;

- on the $28^{\text {th }}$ day of the system operation, the number of users of each of the scenarios equalized.

The presented solutions prove the power of the mechanism of information systems with the help of the multiscenario ideology of functional implementation and will be useful in the development of multi-interface systems with a wide range of users.

This research needs to be repeated after the introduction of more scenarios. The following research should consider the following requirements for the separation of statistics:

- for the control group, which independently selects the display scenario;

- for different types of system users (patients, medical workers, administration of medical institutions);

- for experienced users of the system and beginners.

\section{References}

1. Schaumann, D., Breslav, S., Goldstein, R., Khan, A., Kalay, Y. E. (2017). Simulating use scenarios in hospitals using multi-agent narratives. Journal of Building Performance Simulation, 10 (5-6), 636-652. doi: https://doi.org/10.1080/19401493.2017.1332687

2. Yost, J., Dobbins, M., Traynor, R., DeCorby, K., Workentine, S., Greco, L. (2014). Tools to support evidence-informed public health decision making. BMC Public Health, 14 (1). doi: https:// doi.org/10.1186/1471-2458-14-728

3. Jardim, S. V. B. (2013). The Electronic Health Record and its Contribution to Healthcare Information Systems Interoperability.
Procedia Technology, 9, 940-948. doi: https://doi.org/10.1016/ j.protcy.2013.12.105

4. Non-small Cell Lung Cancer. Early and Locally advanced (2021). NCCN. Available at: https://www.nccn.org/patients/ guidelines/content/PDF/lung-early-stage-patient.pdf

5. Non-small Cell Lung Cancer. Metastatic (2021). NCCN. Available at: https://www.nccn.org/patients/guidelines/content/PDF/ lung-metastatic-patient.pdf

6. CRUK Summary of NICE Cancer referral guidelines - Symptom desk easel. 2020. UK. Available at: https://www.cancerresearchuk.org/ sites/default/files/cancer-stats/nice desk easel interactive march_2020/nice_desk_easel_interactive_march_2020.pdf

7. Tosun, A. B., Kandemir, M., Sokmensuer, C., Gunduz-Demir, C. (2009). Object-oriented texture analysis for the unsupervised segmentation of biopsy images for cancer detection. Pattern Recognition, 42 (6), 1104-1112. doi: https://doi.org/10.1016/ j.patcog.2008.07.007

8. Artamonov, Ye. B., Holovach, Yu. Yu. (2018). Pidkhody do orhanizatsii roboty prohramnoho kompleksu pidtrymky pryiniattia rishen pry likuvanni raku leheniv. Visnyk inzhenernoi akademii Ukrainy, 1, 128-134.

9. Parry, D. (2008). Computerised Decision Support for Women's Health Informatics. Medical Informatics in Obstetrics and Gynecology, 302-314. doi: https://doi.org/10.4018/978-1-60566078-3.ch015

10. Holovach, Yu. Yu. (2019). Otsinka informatyvnosti ta formuvannia informatyvnoho prostoru oznak $\mathrm{v}$ systemi pidtrymky pryiniattia rishen. Visnyk inzhenernoi akademiyi Ukrainy, 4, $130-133$.

11. NCCN clinical practice Guidelines in Oncology. Non-small cell lung cancer. Version 3.2020. NCCN. Available at: https://www2. tri-kobe.org/nccn/guideline/lung/english/non_small.pdf

$\triangle$ Yevhen Artamonov, PhD, Department of Computerized Control System, National Aviation University, Kyiv, Ukraine, ORCID: http:// orcid.org/0000-0002-9875-7372,e-mail: eart@ukr.net

Viktoria Borisevich, Researcher, Ukrainian Research Institute of Special Equipment and Forensic Science of the Security Service of Ukraine, Kyiv, Ukraine, ORCID: http://orcid.org/0000-00034392-314X

Iurii Golovach, Company «Squad», Kyiv, Ukraine, ORCID: http:// orcid.org/0000-0001-9872-8144

$\triangle$ Corresponding author 